\title{
editorial
}

\section{A letter to Darwin}

$\mathrm{D}$ ear Dr Darwin

We were a bit puzzled by your handwritten application for funding as it shows a staggering disregard for our practices and rules relating to requests for research support. We usually receive applications by electronic submission, and they must be received before $5 \mathrm{pm}$ on the closing date. However, we realize that our current instructions do not formally preclude non-electronic communication and therefore we had little choice but to consider your application.

We sent your proposal to a panel of international expert referees who have not worked or published with you during the past 10 years. Their comments are summarized below and we hope that you will find them helpful should you choose to resubmit in the future. Although your project departs from the routine-a refreshing change from modern research projects that tend to be merely incremental steps with no real impact on the universe of relevant knowledge- - am afraid that your application for funding has been rejected.

In the first referee's opinion, the project is a "bizarre exercise". She/he notes that the idea of describing, cataloguing and comparing different species from distant parts of isolated islands is entirely unjustified: "there are many interesting and understudied species within walking distance, the careful analysis of which would be equally valuable," she/he added.

Moreover, the fact that others have catalogued flora and fauna elsewhere removes any semblance of novelty from your proposal. This referee suggests that you carefully analyse the existing literature to gain greater insights before you add to the confusion by discovering even more complex variations in biology. The report also expresses other concerns related to the travel costs, the lack of scientific qualifications of your assistants and the potential for unintended impacts on biodiversity. She/he was not convinced that your previous track record would give reassurance to a high probability of your mission being successful.

Referee two notes that, although the main criterion of our grants is scientific excellence, today's society also requires us to consider the potential societal and, especially, economic consequences-which you have not addressed in your proposal. As the intellectual quotient does not compensate for this omission, referee two is also negative. However, I should add that we are not, in general, antagonistic to proposals that have little chance of stimulating the economy, as shown by our support of the Large Hadron Collider in Geneva, Switzerland.

Referee three is concerned by the lack of a clear hypothesis to guide the enormous research task that you propose: you could end up wasting your time and our money in an open-ended "fishing-exercise"; conversely, you might end up stimulating a very dangerous societal debate. As referee three has pointed out, one obvious implication of your proposal might be that diverse life forms are derived from each other, which has the potential of challenging widely held beliefs in society. Referee three has therefore pointed out the need to balance such a view with the alternative concept of creationism. As a publicly funded council we must remain scrupulously neutral on such sensitive matters.

In a further comment, referee three decries your descriptive approach, which leaves the task of explaining the 'how' to others. His/her view is that any publications resulting from your work will inevitably be acceptable only to lowimpact specialist journals; even worse, they might be publishable only as a monograph. As our agency is judged by the quality of the work that we support-measured by the average impact factor of the papers that result from our funding - this is a strongly negative comment.
We realize that when you read through the full reports from the referees that you will find phrases that might lead you to believe that funding was possible and that our rejection is harsh. There are unusual and therefore intriguing aspects to your idea and the scale of your ambition is impressive. In the final analysis, however, our decision is based on a simple test of whether the work will have a major scientific impact-in other words, will people consider it to be an important piece of knowledge in a hundred years' time? Regretfully, we do not think that your proposed work will yield sufficient insight to meet this requirement. I am therefore very sorry to have to disappoint you on this occasion.

Yours sincerely,

In 1859, the British naturalist Charles Robert Darwin (1809-1882) published his book On the Origin of Species, in which he laid out his theory of evolution by natural selection, based on the observations of species variation that he had made during his five-year voyage on the HMS Beagle. The Origin is now regarded as one of the most influential books in human history. Darwin's powerful and predictive theory of evolution has been widely accepted, and has become the central organizing principle, if not the foundation of modern biology. As the Russian evolutionary biologist Theodosius Dobzhansky (1900-1975) wrote: "Nothing in biology makes sense except in the light of evolution." Luckily, Darwin was not dependent on funding agencies to finance his voyage. This tongue-in-cheek editorial celebrates the 200th anniversary of Darwin's birth on February 12, 1809, at Mount House in Shrewsbury, Shropshire, England.

\section{Frank Gannon \\ This Editorial represents the personal views of Frank Gannon and not those of Science Foundation Ireland or the European Molecular Biology Organization. \\ doi:10.1038/embor.2008.239}

